\title{
Produção de energia elétrica a partir da incineração de resíduos sólidos domésticos usando motor Stirling Alfa caseiro
}

\section{Gabriela Dienne Figueredo Duarte ${ }^{1}$, Caroline dos Santos Cavalcanti ${ }^{1}$, Henrique John Pereira Neves ${ }^{2}$}

${ }^{1}$ Graduanda no Curso de Engenharia Ambiental. Associação Caruaruense de Ensino Superior e Técnico (ASCES). Faculdade ASCES. Av. Portugal, 584. Bairro Universitário. Caruaru-PE (CEP 55016-901).

${ }^{2}$ Associação Caruaruense de Ensino Superior e Técnico (ASCES). Faculdade ASCES. Av. Portugal, 584. Bairro Universitário. Caruaru-PE (CEP 55016-901). E-mail: henriquejohn@yahoo.com.br.

Resumo. A discussão acerca da destinação final incorreta dos resíduos sólidos move a busca por novas tecnologias no Brasil. Uma forma de tratamento extremamente eficiente e bastante polêmica para estes resíduos é a incineração, não descartando a necessidade de políticas públicas que abordem a educação ambiental no país, principalmente na base escolar, para que haja um entendimento por parte da população sobre a importância da redução, da reciclagem, da reutilização e da destinação final correta dos resíduos sólidos. A proposta do projeto de iniciação científica foi produzir energia elétrica a partir da queima de resíduos sólidos domésticos, utilizando um motor tipo Stirling construído com materiais reaproveitados. O país que serviu de inspiração para a realização deste projeto foi a Alemanha, que incinera $40 \%$ dos seus resíduos e faz o reaproveitamento energético eficiente. Durante a execução do projeto surgiu a oportunidade de uma das participantes conhecer esta tecnologia de perto, através de um intercâmbio. Em síntese o presente artigo contempla a experiência do intercâmbio realizado, bem como o alcance dos objetivos propostos no projeto de iniciação científica. Foram construídos um incinerador e um motor termodinâmico, que gerou energia suficiente para acender uma lâmpada de led de $10 \mathrm{~W}$ a partir da combustão dos resíduos selecionados para o processo.

Palavras-chave: Resíduos Sólidos; Incineração; Motor Stirling.

Abstract. Production of electric energy from the incineration of household solid waste using Stirling engine Alpha homemade. The discussion about the incorrect disposal of solid waste moves the search for new technologies in Brazil. A form of extremely efficient processing and very controversial for these wastes is incineration, not ruling out the need for public policies that address the environmental education in the country, especially in school, so there is an understanding among the population about the importance of reducing, recycling, reuse and properly disposal of solid waste. The purpose of the research project was to produce electricity from household waste burning, using a Stirling engine type built with

Recebido:

$11 / 08 / 2016$

Aceito:

27/12/2016

Publicado:

31/12/2016

Acesso Aberto

Artigo completo

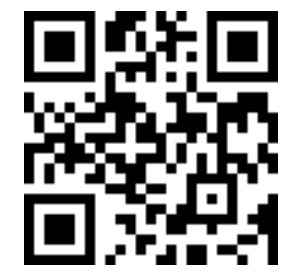

ORCIID

(D) 0000-0001-6558-2425

Gabriela Dienne

Figueredo Duarte

(D) 0000-0001-5466-7933

Caroline dos Santos

Cavalcanti

(D) 0000-0001-5466-7933

Henrique John Pereira

Neves 
recycled materials. The country that was the inspiration for the realization of this project was Germany, which incinerates $40 \%$ of their waste and makes efficient energy reuse. During the project implementation the opportunity arose to one of the participants know this technology through an exchange. Briefly the present article is the experience of the exchange carried out, and the achievement of the objectives proposed in the research project. Was builted an incinerator and a thermodynamic engine, which generated enough energy to light a Led lamp of $10 \mathrm{~W}$ from the combustion of waste selected for the process.

Kyewords: Solid waste; Incineration; Stirling engine.

\section{Introdução}

Segundo o instituto de pesquisa Ipsos (2013), o Brasil ocupa o quarto lugar no ranking dos cinco países mais consumistas do mundo, ou seja, quanto maior for o consumo consequentemente haverá uma maior geração de resíduos. Nesse contexto é alavancado o problema dos resíduos no país, onde só no estado de Pernambuco, 48,1\% dos resíduos sólidos coletados diariamente tem como destinação final os lixões (IBGE, 2000).

Tendo em vista o alto investimento financeiro e a escassez de área necessária e adequada para a implantação de aterros sanitários, principalmente nos pequenos municípios, faz-se de fundamental importância e urgência a busca por tecnologias que sirvam de subsídio para a destinação final dos resíduos sólidos urbanos. Nesse contexto, as chamadas Unidades de Recuperação Energética de Resíduos Sólidos Urbanos (URE), que são usinas de incineração de resíduos com geração de energia, vem sendo apresentadas como solução para o problema da destinação final inadequada dos resíduos sólidos urbanos (Caixeta, 2005). Um exemplo de país que utiliza a tecnologia de reaproveitamento energético dos resíduos através da incineração é a Alemanha.

Entre as principais vantagens do reaproveitamento energético a partir da incineração de resíduos sólidos urbanos está a redução do volume de lixo, a diminuição da emissão de gases estufa, como o metano, que é 21 vezes mais poluente que o $\mathrm{CO}_{2}$, e a ausência de chorume (Rizzo, 2009).
Uma forma barata e simples de incinerar o resíduo sólido, gerando energia elétrica é utilizando um motor tipo Stirling (Alfa, Beta ou Gama), pois sua montagem pode ser feita com resíduos sólidos, bem como seu funcionamento e operação são fáceis, necessitando apenas de uma fonte de calor para geração de ar quente, que o fará funcionar (Lourencini et al., 2013).

No decorrer do ano da pesquisa (2015), surgiu a oportunidade de uma das participantes do projeto conhecer a tecnologia de incineração desenvolvida na Alemanha através de um programa de intercâmbio promovido pelo Município de Caruaru-PE. Dessa forma, o presente artigo tem como objetivo apresentar os resultados obtidos com a incineração dos resíduos sólidos e a produção de energia elétrica, a partir do funcionamento do motor Stirling, além de compartilhar as experiências mais amplas que puderam ser vivenciadas.

\section{Metodologia}

\section{A realização do intercâmbio}

Em 2007, foi assinada uma parceria de cooperação técnica entre o Município Brasileiro de Caruaru-PE e o Distrito Alemão de Hof-Baviera e, a partir de 2011, esta parceria passou a envolver também ações de Educação Ambiental escolar, com foco na construção de consciência ambiental voltada principalmente ao gerenciamento de resíduos sólidos.

As atividades previstas na parceria consistem na realização do projeto denominado "Gerenciamento de resíduos sólidos e Educação Ambiental”, composto por duas fases, a Fase Norte e a Fase Sul, 
onde se promove um intercâmbio entre jovens brasileiros e alemães que estejam engajados na temática das questões ambientais, apresentem um projeto que contemple a área de resíduos sólidos e dominem, no mínimo, uma segunda língua, permitindo uma boa comunicação nas duas fases do projeto.

Em dezembro de 2014, no portal eletrônico da faculdade ASCES, foi anunciado o lançamento do edital de inscrição para o Programa de Intercâmbio ASA Kommunal Sul-Norte (ZMS, 2014). Entre as exigências contidas no edital estava a de apresentar um projeto que contemplasse a área de resíduos sólidos. $\mathrm{Na}$ realização da inscrição para concorrer a uma das duas vagas disponíveis, foi apresentado o projeto "Produção de energia elétrica a partir da incineração de resíduos sólidos domésticos usando motor Stirling alfa caseiro”, que, por sua vez, já havia sido aprovado pelo comitê científico do INICIA (Programa de Iniciação CientíficaAssociação Caruaruense de Ensino Superior e Técnico-ASCES).

Após a obtenção da vaga, o programa de intercâmbio foi iniciado no mês de abril de 2015 e seguiu até julho de 2015, a execução do projeto no decorrer dos três meses tratou da preparação conceitual, realização de visitas técnicas, treinamentos e práticas na área de reaproveitamento térmico de resíduos sólidos, bem como na área de gerenciamento destes resíduos e a educação ambiental na Alemanha, país que serviu de inspiração para a iniciativa de realização do referido projeto de iniciação científica.

Foi uma fase preparatória bastante enriquecedora e necessária, uma vez que o grupo estava trabalhando com dois países histórica e culturalmente diferentes. Durante esta fase também foram desenvolvidas as primeiras atividades do projeto, que consistiram em visitas a várias escolas alemãs para desenvolvimento de atividades de educação ambiental, além de visitas técnicas em todos os departamentos ambientais consorciados ao município e em especial à usina de Schwandorf, que executa o tratamento térmico e o reaproveitamento energético dos resíduos sólidos incineráveis e não-reaproveitáveis.

Essa usina incinera 23 toneladas de resíduos por hora e dessa forma é capaz de gerar energia elétrica que abastece a rede pública da cidade de Schwandorf, além de outros benefícios para a cidade e indústrias vizinhas (ZMS, 2014). A fase sul teve a mesma duração e o grupo dos participantes se reuniu novamente para a realização das mesmas atividades sobre consciência ambiental em escolas municipais caruaruenses e visitas técnicas em todos os departamentos ambientais do município Brasileiro, bem como houve a conclusão do projeto de Iniciação Científica.

\section{A concepção do incinerador}

Foi construída uma fornalha com $28 \mathrm{~cm}$ de diâmetro e $38 \mathrm{~cm}$ de altura montada sobre uma base de churrasqueira pequena de $36 \mathrm{~cm}$ de diâmetro por $16 \mathrm{~cm}$ de altura, onde se colocou o lixo para ser queimado, sendo sua saída canalizada com uma tubulação de zinco de $10 \mathrm{~cm}$ de diâmetro e $85 \mathrm{~cm}$ de altura, estruturada com um quebra chama para evitar que o fogo proveniente da combustão ultrapassasse a canalização e danificasse o filtro manga, todas as junções da estrutura precisaram ser vedadas com material resistente a alta temperatura para que não houvesse nenhum escape de fumaça durante a operação, a tubulação serviu para concentrar a fumaça produzida na queima do lixo (ver Figura 1).

Um filtro tipo manga de tecido de algodão, com dimensões de $10 \mathrm{~cm}$ de diâmetro por $40 \mathrm{~cm}$ de altura foi utilizado para tratar a fumaça produzida. Após o tratamento da fumaça, a mesma passou por uma chaminé, com saída de $10 \mathrm{~cm}$ de diâmetro e $85 \mathrm{~cm}$ de altura, para concentrar toda a fumaça quente que serviu para aquecer os cilindros do motor e fazê-lo funcionar (ver Figura 2).

Na Figura 2 é possível observar a alteração da coloração da fumaça antes e após passar pelo filtro tipo manga (antes escura e depois esbranquiçada). 


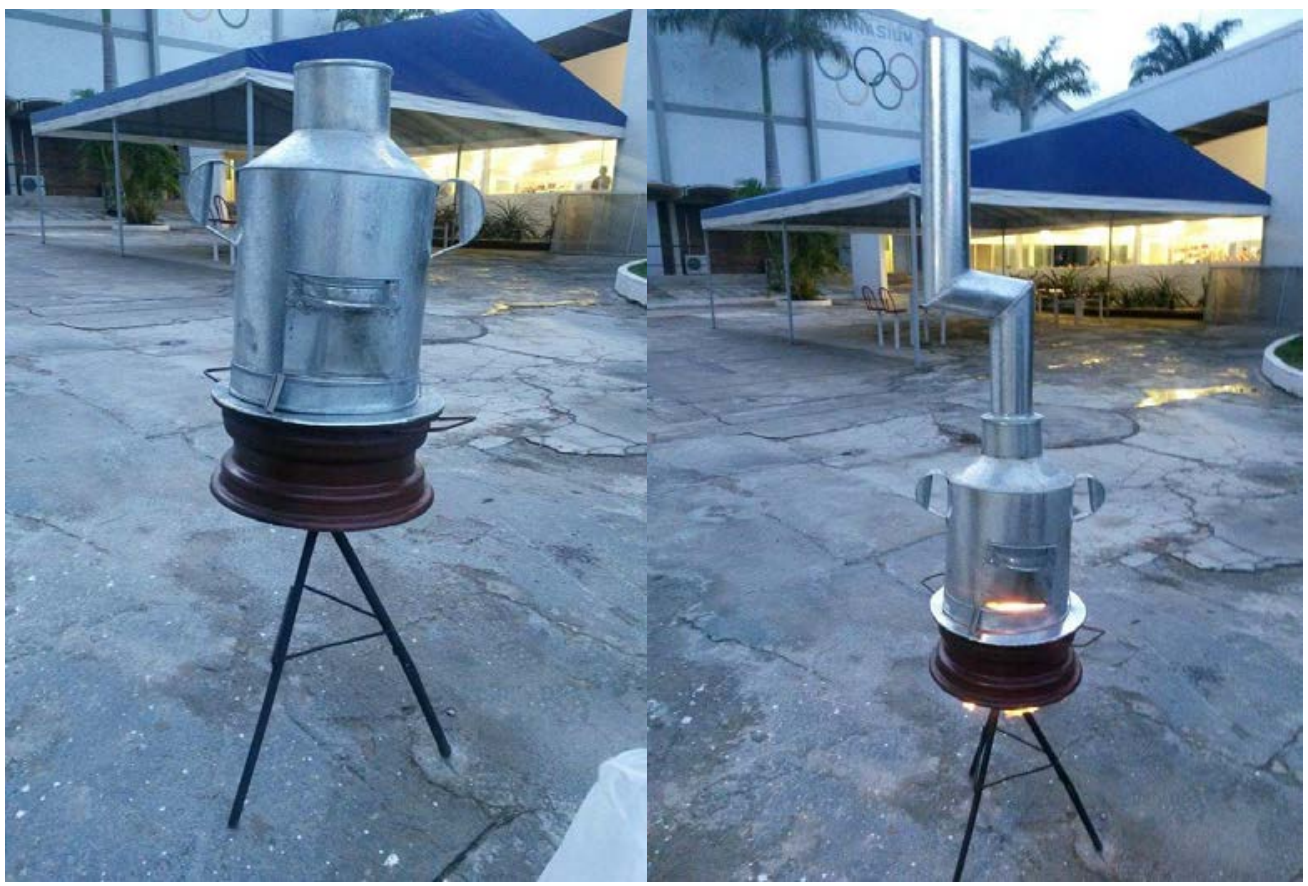

Figura 1. Incinerador em processo de montagem. Fonte: Autoria própria

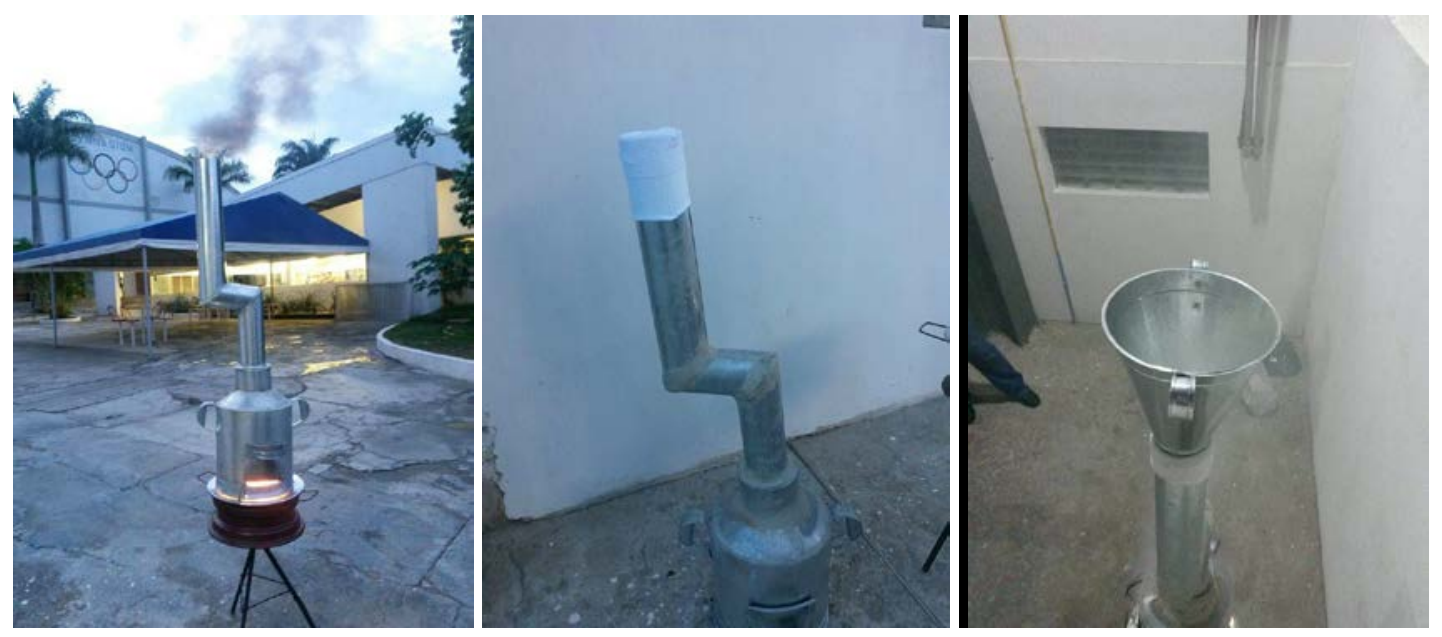

Figura 2. Colocação do filtro tipo manga.

A seleção dos resíduos utilizados Juntou-se nas residências das pessoas envolvidas neste projeto todo resíduo sólido descartável, por um período de um mês, para se ter uma quantidade de, no mínimo, cinco quilos para iniciar o funcionamento do equipamento que gerou energia elétrica. Por apresentarem menor resistência ao dano no processo de combustão, os materiais selecionados foram papéis, papelões e plásticos, não sendo 
utilizados para este trabalho resíduos sólidos oriundos de higiene pessoal (resíduos sanitários).

\section{A concepção do motor}

Inicialmente foi proposta a concepção de um motor stirling alfa caseiro, porém por não ter sido fácil o acesso aos materiais para a montagem e pelo curto prazo de tempo para o desenvolvimento do projeto, o tipo de motor foi modificado para o stirling gama caseiro (Figura 3).

O motor stirling gama caseiro foi constituído com materiais reutilizados, como por exemplo latas de cerveja e refrigerantes, CDs e tampas de embalagens. $\mathrm{O}$ processo de montagem do cabeçote, cilindro, pistão de trabalho e deslocador, sistema de resfriamento, virabrequim e o volante, foram feitos de forma totalmente artesanal.

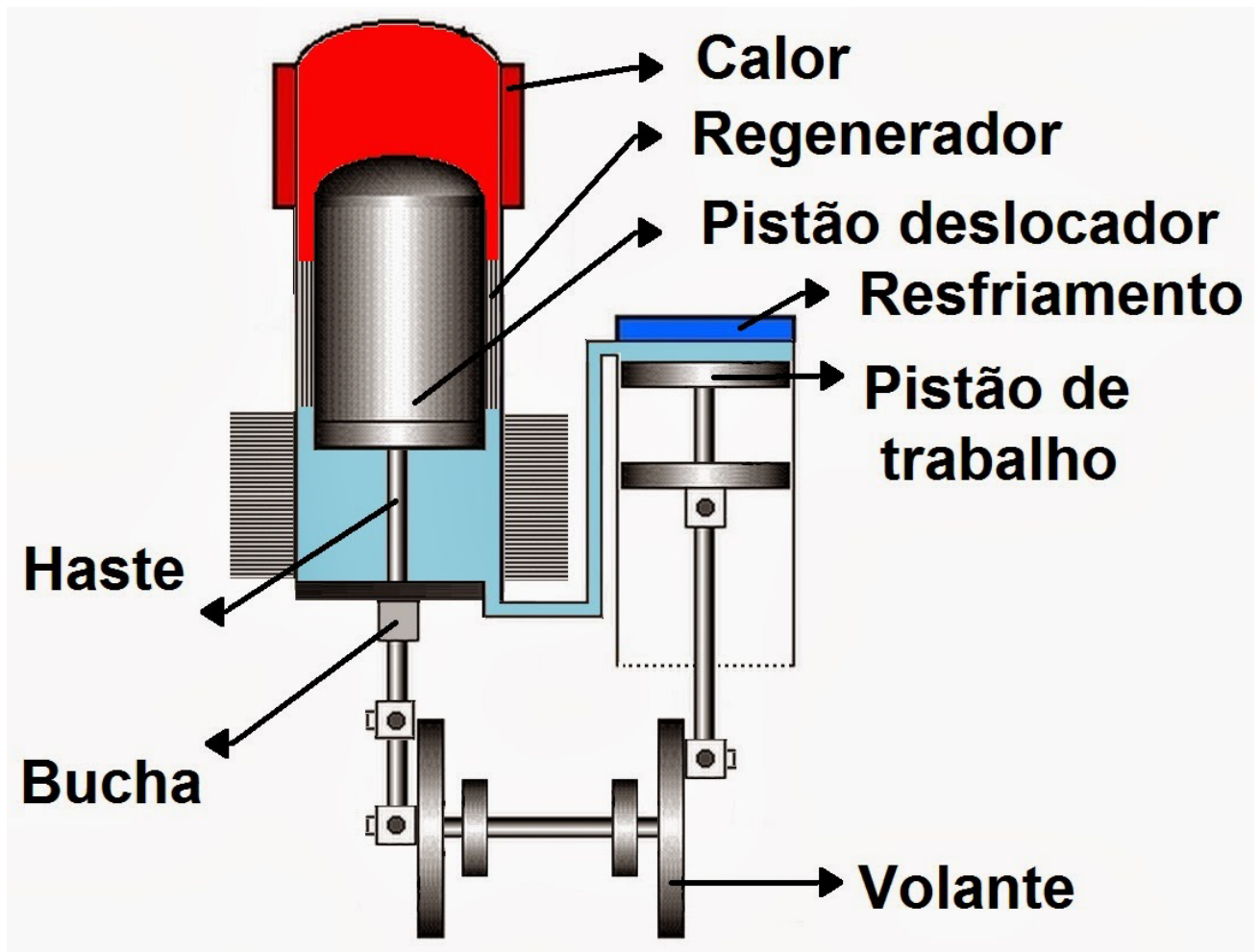

Figura 3. Motor do tipo Stirling Gama. Fonte: Wagner (2014).

\section{Resultados e discussão} intercâmbio

As atividades desenvolvidas no

A fase norte foi realizada no município alemão, no período de abril a julho de 2015, no decorrer desses três meses, os participantes estiveram presentes nos três seminários do programa ASA, estes são seminários de formação para o projeto como mencionado anteriormente. Os eixos temáticos abordados nos seminários foram estruturas de poder, racismo, colonialismo, desenvolvimento sustentável entres outros, a fim de preparar os participantes para desenvolver o projeto no sul e norte global, uma vez que são localidades completamente diferentes, histórico e culturalmente.

Durante essa fase as primeiras atividades do projeto consistiram em visitas a 15 escolas alemãs para desenvolvimento 
das atividades de educação ambiental relacionada ao gerenciamento de resíduos sólidos, além de visitas técnicas em todos os departamentos ambientais consorciados ao município, por exemplo o ponto móvel de coleta de resíduos problemáticos, não recicláveis (Figura 3), que são encaminhados para a incineração, e visitas em especial à usina de Schwandorf.

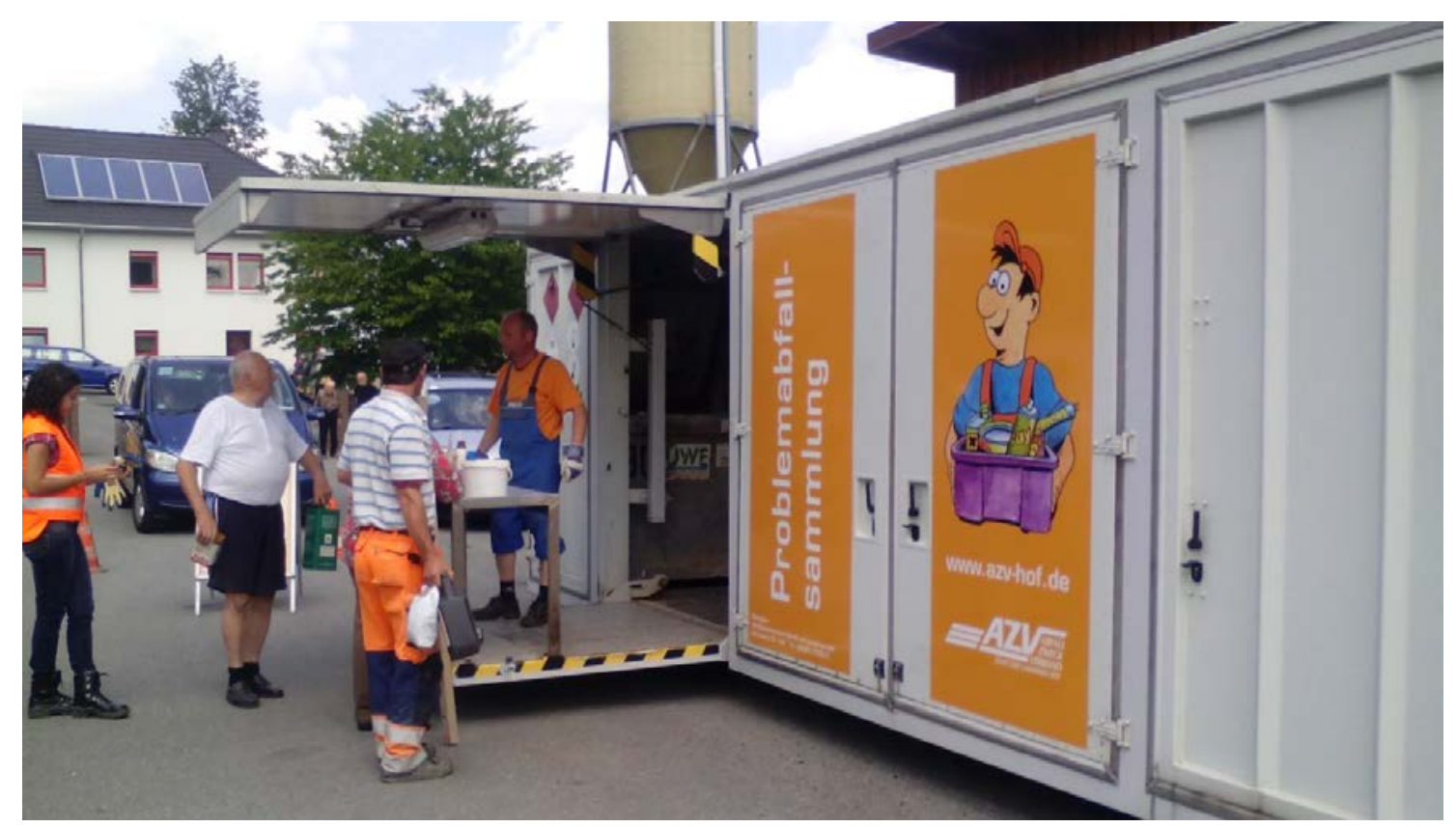

Figura 4. Ponto móvel de coleta de resíduos problemáticos, não recicláveis. Retirada em 14 de maio de 2015.

A usina de Schwandorf é envolvida em um consórcio composto por 15 membros, a mesma atende a um território de aproximadamente $14.000 \mathrm{~m}^{2}$ (o que corresponde a um quinto da Baviera). Cerca de 1.649.000 habitantes têm seus resíduos sólidos domiciliares ou resultantes de atividades comerciais dispostos nessa usina de Schwandorf (ZMS, 2014). A usina possui a capacidade de realizar o tratamento térmico e o reaproveitamento energético de até 450.000 t/a dos resíduos sólidos incineráveis e não-reaproveitáveis, a mesma possuindo 4 caldeiras, a caldeira 4 , por exemplo, incinera $23 \mathrm{t}$ de resíduos por hora (ZMS, 2014). A energia calorífica obtida no processo de incineração gera vapor na caldeira, uma parte é fornecida como vapor de processo para indústrias vizinhas e três turbinas geram energia elétrica que alimenta a rede pública (ZMS, 2014). 


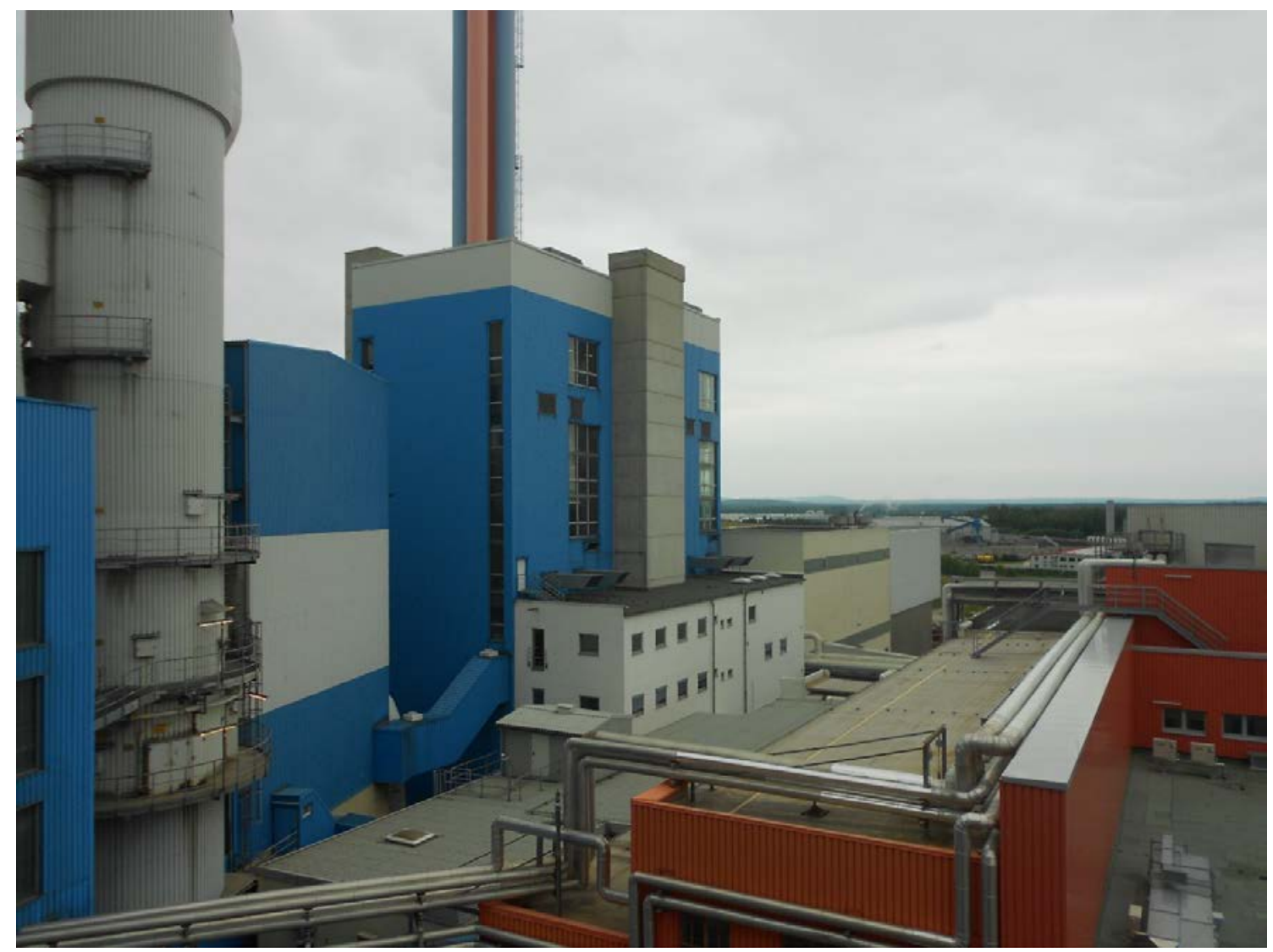

Figura 5. Usina de Schwandorf. Retirada em 01 de junho de 2015.

Desde 1996, a usina abastece igualmente a rede de aquecimento à distância do serviço de abastecimento de água e aquecimento de Schwandorf. Esse aproveitamento contribui para economizar energia primária, evitar emissões e ajudar na prevenção do clima. O tratamento da fumaça atende aos rígidos parâmetros relativos à qualidade do ar (ZMS, 2014).

A fase sul teve a mesma duração e o grupo dos participantes se reuniu novamente para a realização das mesmas atividades sobre educação ambiental em escolas municipais caruaruenses sobre a importância do bom gerenciamento de resíduos sólidos, com a finalidade de cativar a consciência ecológica nas crianças para que a realidade ambiental do munícipio possa ser melhorada, além das visitas técnicas em todos os departamentos ambientais do município brasileiro. A fase sul do Programa ASA Kommunal Sul-
Norte foi executada durante os meses de outubro, novembro e dezembro.

O funcionamento do incinerador e produção de energia elétrica a partir do calor

A fornalha do incinerador foi alimentada com resíduos de papel (folhas de jornal, papelão etc), o calor proveniente da queima destes resíduos chegou a uma temperatura superior a $300{ }^{\circ} \mathrm{C}$. A combustão dos resíduos resultou em cinzas, vapor e calor.

O motor Stirling gama caseiro funciona como uma máquina térmica de combustão externa que utiliza qualquer fonte calorífica como combustível e gases atmosféricos como flui do de trabalho para converter calor em trabalho mecânico. O motor foi colocado logo acima da chaminé com o cilindro posicionado na sua saída para que a fumaça quente pudesse 
aquecê-lo fazendo o motor funcionar. Foi ligado no inversor do motor uma lâmpada de led de $10 \mathrm{~W}$, observando-se a correta geração da energia elétrica, que foi suficiente para acender a lâmpada de led (Figura 6). Quanto às cinzas, o balanço de massa mostrou que a cada um $1 \mathrm{~kg}$ de resíduo incinerado sobraram $0,059 \mathrm{~kg}$, sendo o volume inicial reduzido em $41 \%$. E o vapor é tratado pelo filtro manga.

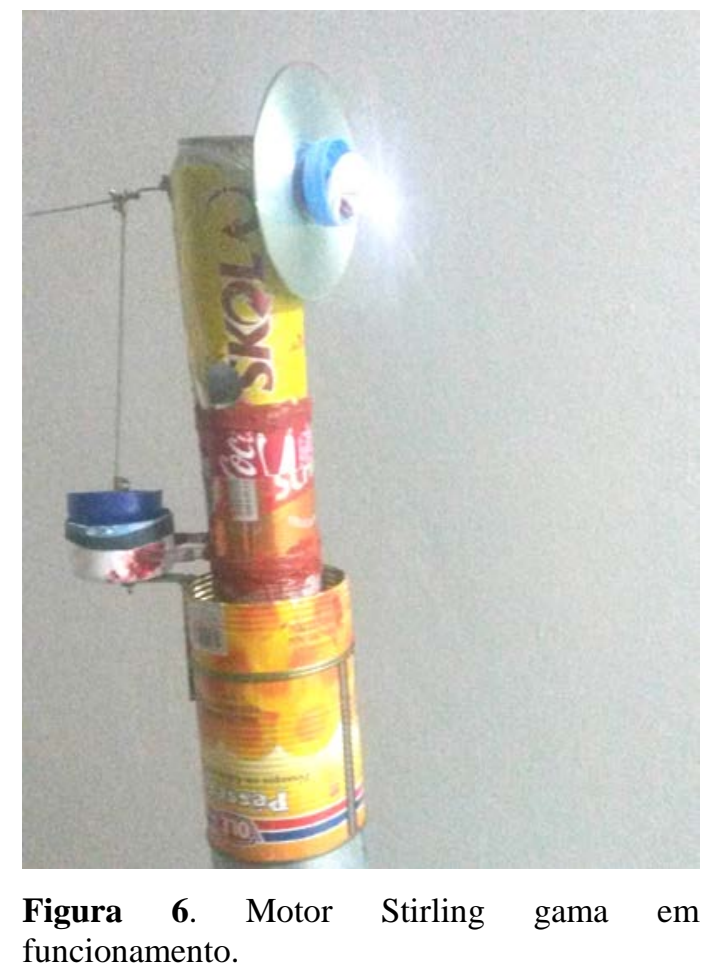

\section{Considerações finais}

Em virtude do que foi mencionado, conclui-se que a experiência de conhecer de perto uma realidade que serviu de inspiração para a criação do projeto de Iniciação Científica da ASCES (Associação Caruaruense de Ensino Superior e Técnico) enriqueceu a sua execução do mesmo, pois possibilitou a percepção da necessidade de políticas públicas direcionadas a educação ambiental voltadas para os resíduos sólidos. Observou-se a falta de instrução na rede escolar no município de Caruaru-PE relacionada ao tema em questão, o que influencia de forma sistemática no processo de incineração dos resíduos, sendo a base do processo a redução na geração dos resíduos e a segregação destes em secos e úmidos.

O protótipo do incinerador funcionou de forma satisfatória e similar ao que foi visto na Alemanha, atendendo aos objetivos iniciais do projeto, geração de energia a partir da incineração de resíduo sólido. Os resíduos foram reduzidos significativamente, a fumaça produzida foi tratada pelo filtro manga e a energia calorífica produzida foi capaz de acender uma lâmpada de led de $10 \mathrm{~W}$. E as cinzas que restaram são consideradas material inerte.

\section{Declaração de conflito de interesses}

Os autores declaram não haver conflitos de interesses.

\section{Referências}

Caixeta, D. M. Geração de energia elétrica a partir da incineração de lixo urbano: o caso de Campo Grande/MS. Brasília: UNB, 2005.

IBGE. Pesquisa Nacional de Saneamento Básico. Quantidade diária de lixo coletado, por unidade de destino final do lixo coletado, segundo as grandes regiões, unidades da federação, regiões metropolitanas e municípios das capitais - 2000. Disponível em: $<$ http://www.ibge.gov.br/home/estatistica/popul acao/condicaodevida/pnsb/lixo_coletado/lixo_c oletado110.shtm>. Acesso em: 17 set. 2015.

IPSOS. Global attitudes on materialism, finances and family. 2013. Diponível em: $<$ http://www.ipsos-na.com/newspolls/pressrelease.aspx?id=6359>. Acessado em 19/09/2015.

Lourencini, A.; Bisi, C. S.; Petri, L. A.; Calenzani, L. L.; Salarolli, L. R.; Salarolli, M. P.; Salarolli, P. F.; Ramos, R. X.; Xavier, L. A. Motor Stirling: o futuro da geração de energia elétrica. Pelotas: EEEFM Coronel Gomes de Oliveira, 2013. Disponível em: <http://s7226b29e809f8138.jimcontent.com/do wnload/version/1433641521/module/64364386 68/name/STIRLING trabalho final.pdf $>$. Acesso em: 20 set. 2015.

Rizzo, R. B. Usina de lixo com geração de energia é alternativa para destino dos resíduos sólidos. São Paulo: Revista Fator Brasil, 2009. 
Wagner, L. Manual do motor Stirling. Como é um motor stirling alfa. 2014. Disponível em: <http://manualdomotorstirling.blogspot.com.br/ 2014/04/como-e-um-motor-stirling-alfa.html>. Acesso em: 20 set. 2015.

ZMS - Zweckverband Müllverwertung Schwandorf. Consórcio Intermunicipal para o Aproveitamento de Resíduos Sólidos. Schwandorf, Deutshland: ZMS 2014. Disponível em: <http://z-ms.de/downloads/2015portug.pdf>. Acesso em: 01 out. 2015.

Informação da Licença: Este é um artigo Open Access distribuído sob os termos da Licença Creative Commons Attribution, que permite uso irrestrito, distribuição e reprodução em qualquer meio, desde que a obra original seja devidamente citada.

Rev. Bras. Gest. Amb. Sustent., 2016, v. 3, n. 6, p. 317-325. 